\title{
Practice of Manual Intrauterine Aspiration for Post- Abortion Care (PAC): Prospective Study of 137 Cases at Owendo's CHU Maternity Hospital
}

\author{
Sima Ole $B^{* 1}$, Mounguengui $\mathrm{CO}^{1}$, Obame $\mathrm{R}^{3}$, Madi Tangani $\mathrm{G}^{1}$, Mba Edou $\mathrm{G}^{1}$, Ebanga $\mathrm{L}^{1}$, Mewie Lendzinga $\mathrm{A}^{1}$, \\ Bang Ntamack JA', Mayi Tsonga $\mathrm{S}^{2}$, Ngou Mve Ngou JP' and Meye $\mathrm{JF}^{2}$ \\ ${ }^{1}$ Owendo Obstetric Gynecology Service, Owendo, Africa \\ ${ }^{2}$ Department of Obstetric Gynecology Libreville Medical School, Owendo, Africa \\ ${ }^{3}$ Owendo's CHU Anesthesia and Resuscitation Service, Owendo, Africa
}

*Corresponding author: Boniface Sima Ole, Department of Obstetric Gynecology, Owendo, Gabon.

Received Date: July 08, 2019

Published Date: July 17, 2019

\begin{abstract}
Objective: Describe and analyze the practice of MIA in our environment with a view of contributing to the reduction of morbidity and maternal mortality.

Methodology: Descriptive and analytical cross-sectional study, conducted at the motherhood of Owendo's CHU for 24 months, from 1 January 2017 to 31 December 2018. All women who consulted for incomplete abortions with gestational terms below 12 SA were enrolled. The management consisted of uterine evacuation by MIA. For each patient we studied socio-demographic and pregnancy variables, MIA practice, morbidity and maternal mortality.
\end{abstract}

Results: One hundred and thirty-seven patients were eligible, representing a frequency of 5.5\%. The average age of patients was $26.58 \pm 1.68$ years, with predominance for $16-24$ years old. The mean gestational age was $8.13 \pm 1.57 \mathrm{SA}, 76$ cases $(55.47 \%)$ were aborted and 69 cases $(90.79 \%)$ were clandestine. The treatment consisted of uterine evacuation. In 89 cases (64.96\%). This was done with the electric vacuum cleaner (EMIA) versus 48 cases (35.04) for SMIA. The use of general anesthesia was necessary for 12 cases (8.75\%), medical resuscitation 9 cases $(6.57 \%)$ and resuscitation 1 case $(0.73 \%)$ with p-value equal to 0.001 and 0.01 respectively for induced abortions. The average length of hospital stay was $1.8 \pm 2.08$ hours. No maternal deaths were observed.

Keywords: Abortion care after abortion; MIA-Maternal death

\section{Introduction}

According to the WHO, induced abortion today is one of the frequent complications of the first trimester of pregnancy and one of the pillars responsible for maternal deaths in low-income countries [1,2]. Worldwide, 20 million at-risk abortions and 80000 deaths per year are recorded or $1 / 8$ deaths. Africa has 3.7 million and 23 miles of deaths as a result of these complications [3]. Abortion is a public health problem that affects women of all ages, but especially young women who are less financially well off and less informed about family planning services. Moreover, these are most often advanced clinical forms and their management is often delayed [1]. This delay is multifactorial. In 2009, a series produced by Mayi-Tsonga and al. At the Libreville University Hospital showed that women died from unsafe abortions. These deaths were related to long delays in receiving emergency obstetric care (EOC) [4]. The authorities then supported the recommendations of the Hospital Committee on Maternal Mortality, which called for shortening delays and also improving the care of women suffering from abortion complications. This explains why the Gabonese Society of Obstetric Gynecology and Reproduction (GSOGR) have agreed to participate in the FIGO initiative for the prevention of unsafe abortions and their consequences [5]. For example, hospitals have introduced manual intra-uterine aspiration training (MIA) into health care provider. It is a method of uterine evacuation that mobilizes few means, accessible by all health formations and preserves fertility by avoiding immediate complications. It can be made using syringe 
(SMIA) or electric vacuum cleaner (EMIA). Since then, MIA has been widely used in all health units in Libreville.

The purpose of our study was to describe and analyze the practice of MIA in motherhood of Owendo's Teaching hospital with a view to contribute to the reduction of maternal morbidity and mortality.

\section{Patients and Methods}

This is a descriptive and analytical cross-sectional study carried out at the motherhood of Owendo's teaching hospital in the period of 24 months from 1 January 2017 to 31 December 2018.

For the description and recruitment of the sample, we have chosen the concepts of spontaneous, induced, therapeutic, ongoing, incomplete, molar or aborted/clear egg abortions. The definition of abortion is that contained in the International Classification of Diseases.

The equipment for the intrauterine suction consists of either a 50 cc vacuum syringe (SMIA) or an electric vacuum cleaner (EMIA), canules adapted according to gestational age, a Pozzi plier and the necessities for local asepsis. A simple gesture made in the delivery room, in the emergency room or in the operating room. Anesthesia may be necessary.

After a vulvo-vaginal asepsis, the cervix is exposed after a speculum is laid and then taken from it by the pliers of Pozzi. The choice of the cannula depends on the gestational age and the degree of opening of the cervix. A gentle and careful aspiration is achieved until the cry of the endometrial is obtained and pain is created. Antibiotic therapy and contraceptive counseling were systematic. A control ultrasound was done at J7.

Eligible for the study were all women referred, self-employed or hospitalized requiring uterine evacuation and having a gestational term of less than or equal to 12 weeks of amenorrhea (WA).

The database was represented by patient records, WHO and (IFGO) International Federation of Gynecology and Obstetrics records of abortions, and hospital records of surgery and discharge. Patients with complete abortions, those with closed cervix, pregnancy with a gestational term greater than $12 \mathrm{SA}$, progressive intrauterine pregnancy, and those with incomplete records were excluded.

An individual data collection sheet was prepared and the following variables were studied: age, occupation, parity, gestational age, desire or lack of pregnancy, type of abortion, abortive product, functional signs, hemodynamic status, complementary examinations (blood type, NFS, pelvic ultrasound, histopathology), use of anesthesia, type of anesthesia, gesture (SMIA or EMIA), the duration of the intervention, the need for a medical resuscitation, complications (hemorrhagic, shock, uterine perforation, debris retention), the period of care, the length of hospital stay and maternal death.

To capture the data collected, we used Epi-infoTM software version 7.1.3.3. The processing and analysis of these were done with
SPSS version 23 software. Results are expressed as a percentage for quantitative variables and on average standard deviation for qualitative variables. The Chi2 test compared the qualitative values and the Student $t$ test for the quantitative values comparison. The $\mathrm{p}$ value of the probability was found to be significant for a value $\leq$ 0.05 .

\section{Results}

During the study period, 232 abortions and 4219 deliveries were performed at the Owendo UCHF maternity hospital, a frequency of 5.5\%. 137 cases (59.05\%) were retained.

\section{Sociodemographic characteristics and those of pregnancy}

The average age of patients was $26.58 \pm 1.68$ years. Young women aged 16 to 24 were in the majority, $67.15 \%$ had a secondary school level and $62.77 \%$ were single. The average parity was $1.92 \pm 1.21$ pares with extremes 0 to 10 pares, half was pauciparous (Table I). The mean gestational age was $8.13 \pm 1.57 \mathrm{SA}$ with extremes of 5 to 12 SA. In 75 cases (54.74\%), pregnancy was unwanted and when abortion was induced (55.47\%), it was illegal in 69 cases (90.79\%). In this case, misoprostol was the most widely used abortive product (69.56\%).

\section{Clinical and paraclinic characteristics}

The association pain and metrorrhage was the most recovered functional sign (89.05\%) and 22.63\% was in shock. Echography was the often-requested diagnostic paraclinic examination (64.9\%) and only $8.75 \%$ of the abortion product was addressed to histological analysis (Tables 2\&3).

Table 1: Sociodemographic characteristics.

\begin{tabular}{|c|c|c|}
\hline Variables & $\mathbf{n}$ & $\%$ \\
\hline \multicolumn{3}{|l|}{ Age (an) } \\
\hline $16-24$ & 61 & 44,52 \\
\hline $25-35$ & 55 & 40,14 \\
\hline $36-40$ & 15 & 10,95 \\
\hline Plus de 40 & 6 & 4,38 \\
\hline \multicolumn{3}{|l|}{ Levels of education } \\
\hline Not in school & 11 & 8,03 \\
\hline Primary & 4 & 2,92 \\
\hline Secondary & 92 & 67,15 \\
\hline Greater than & 30 & 22 \\
\hline \multicolumn{3}{|l|}{ Marital status } \\
\hline Single & 86 & 62,77 \\
\hline Concubination & 30 & 22 \\
\hline Married & 21 & 15,33 \\
\hline \multicolumn{3}{|l|}{ Party } \\
\hline 0 & 43 & 31,38 \\
\hline $1-3$ & 69 & 50,37 \\
\hline 6-Apr & 14 & 10,22 \\
\hline$>6$ & 11 & 8,03 \\
\hline \multicolumn{3}{|l|}{ Origin } \\
\hline Home & 112 & 81,75 \\
\hline
\end{tabular}




\begin{tabular}{|c|c|c|}
\hline Hospitalised & 3 & 2,19 \\
\hline Reference & 22 & 16,06 \\
\hline Total & 137 & 100 \\
\hline
\end{tabular}

Table 2: Clinical and paraclinic characteristics.

\begin{tabular}{|c|c|c|}
\hline Variables & n & $\%$ \\
\hline \multicolumn{3}{|l|}{ Type of abortion } \\
\hline Spontaneous & 61 & 44,53 \\
\hline Provoked & 76 & 55,47 \\
\hline Clandestin & 69 & 90,79 \\
\hline Molar & 2 & 2,63 \\
\hline Therapeutic & 5 & 6,58 \\
\hline Abortive product & 11 & 8,03 \\
\hline Misoprostol & 48 & 69,56 \\
\hline Others & 21 & 30,44 \\
\hline Functional signs & 30 & 22 \\
\hline Hemorrhage & 93 & 67,88 \\
\hline Pain/bleeding & 122 & 89,05 \\
\hline Without & 11 & 8,03 \\
\hline Shoc state & 21 & 15,33 \\
\hline Yes & 31 & 22,63 \\
\hline No & 106 & 77,37 \\
\hline Paraclinic balance & 69 & 50,37 \\
\hline Echography & 89 & 64,9 \\
\hline NFS & 101 & 73,72 \\
\hline BHCG & 37 & 27 \\
\hline Histopathology & 12 & 8,75 \\
\hline Hospitalised & 3 & 2,19 \\
\hline Reference & 22 & 16,06 \\
\hline Total & 137 & 100 \\
\hline
\end{tabular}

Table 3: Treatment.

\begin{tabular}{|c|c|c|}
\hline Processing & $\mathbf{n}$ & $\%$ \\
\hline \multicolumn{3}{|l|}{ AMIU } \\
\hline EMIA & 89 & 64,96 \\
\hline SMIA & 48 & 35,04 \\
\hline \multicolumn{3}{|l|}{ Provider } \\
\hline Gynecologist & 22 & 16,06 \\
\hline Resident & 115 & 83,94 \\
\hline Midwife & 0 & 0 \\
\hline General anesthesia & 12 & 8,75 \\
\hline Medical rehabilitation* & 9 & 6,57 \\
\hline Stay in resuscitation** & 1 & 0,73 \\
\hline
\end{tabular}

${ }^{*},{ }^{* *} p=0,001$ et 0,01 in case of induced abortion

\section{Treatment}

The treatment consisted of uterine evacuation and was carried out in all cases by MIA. In 89 cases (64.96\%), this is achieved by the electric vacuum cleaner (EMIA) versus 48 cases (35.04) for SMIA. The use of general anesthesia (GA) was necessary for 12 cases (8.75\%), medical resuscitation 9 cases $(6.57 \%)$ and resuscitation 1 case $(0.73 \%)$ with p-value equal to 0.001 and 0.01 respectively for induced abortions.

\section{Deadlines for care and mortality}

The average time between presentation and support was $65.80 \pm 20.312$ minutes, with extremes of 15 and 120 minutes. In the first 5 hours, 82 cases (59.85\%) were taken care of. The average duration of the intervention was $12.7 \pm 3.5$ minutes for SMIA versus $6.25 \pm 1.42$ minutes. There is a relationship between the practical manual suction type and the duration of the procedure $(\mathrm{p}<0.001)$. One patient $(0.73 \%)$ was hospitalized in intensive care. She was a patient who had had a hemorrhagic abortion with hemodynamic shock. She received an EMIA under AG, a blood transfusion and a 48-hour resuscitation period. The average length of hospital stay was $0.8 \pm 2.08$ days with extremes of 6 to 72 hours. Complications of hemorrhage or uterine perforation were not observed. In contrast, an ovular debris retention was observed at J7 consultation. This was especially observed because the aspiration was manual $(10.42 \%$ vs. $0 \%, \mathrm{p}<0.000$ ). No maternal deaths were observed.

\section{Discussion}

\section{Impact}

At-risk abortion is a public health problem in our country. In recent years, according to the latest EDSG-II, the percentage of abortions among women of childbearing age increased from $23 \%$ in 2000 to $43 \%$ in 2012 [6]. The hospital figures do not reflect its real impact. We found 5.5 percent. $\mathrm{C}$ and incidence are well below those found by Nouhoum in Ségou and Andriamady in Madagascar by 10.2 and $9.6 \%$ respectively [7,8]. As reported by Mayi-Tsonga and coll, the domestic use of misoprostol, the abundance of cases not reported during guards and the increase of obstetric emergency centers in our country contribute to the relative decline in the incidence of abortions [3]. Rigorous management of the IFGO abortion register, digitization of records and networking of care centers would help to highlight the real impact of abortions in our environment. In addition, other approaches as proposed by Gilda Sedgh must be applied [9].

\section{Socio-demographic characteristics of the sample}

Our study found that the average age of women who had abortions was $26.58 \pm 1.68$ years, with a predominance among the 16-24 age groups (44.52\%). This figure is close to those of other series, as found by Moussa Nouhoum, Andriamady and MayiTsonga, et al [4] in Ségou, Madagascar and Libreville respectively $[3,7,8]$. The subpopulation of young women is the most vulnerable to abortion. They are willingly single (62.77\%), have a high level of education (89.15\%) and already 2 or 3 children (50.37\%). These figures are found in other series in the subregion $[7,8,10]$. The level of education does not seem to guarantee an understanding of the risks associated with abortions (90.79\% caused). Family planning methods must be included in secondary school curricula as well as STI control. Moreover, knowledge and acceptability of contraception remain low in our regions $[2,7,11]$. This body of weightlessness can be reduced by the amendment of the abortion law which remains restrictive in our countries and all the key points noted by experts from West and Central Africa [12]. This will provide access to information and practice in surgical conditions. This observation is 
old and persistent. Several sets of authors from sub-Saharan Africa noted: in Libreville in 1989, in Dakar in 1998 and recently by MayiTsonga in Libreville in 2014 [13,14,15].

\section{The clinical picture}

The majority of patients in our series came from their homes and the association pelvic and metrorrhage pains (89.05\%) was the frequent reason for consultation. This finding is identical to that made by Moussa Nouhoum and Andriamady [7,8]. Advanced clinical forms with a state of shock are increasingly less observed (22.63\% in our series). They were the only ones in the old series and are strongly associated with induced abortions $(p=0.000)[10,13]$. The use of misoprostol, as Mayi-Tsonga, et al [17]. points out, has probably contributed to the reduction of these clinical forms and has improved the prognosis of induced abortions [16,17]. The use of ultrasound does not seem useful for the diagnosis of uterine vacuity, even if we always do. An exclusive clinical evaluation alone is sufficient to decide on the care.

\section{Support}

Endouterine evacuation is performed entirely by manual suction with a satisfactory turnaround time $(65,8 \pm 20,312)$. This period was on average 18 hours in 2008 in a series produced by Mayi at the Libreville UC compared to 1.8 hours in 2012 after the introduction of manual aspiration [16]. This technique is expensive, easy and less restrictive. It has succeeded in replacing the endouterine evacuation by picking up a particular organization (a check-up, general anesthesia, a functional block, a picking box, compulsory hospitalization, qualified staff), which has increased the cost, occupancy of beds and delays the care.

The management of abortions has changed a lot in our practices. Between 1989 and today. This has gone from endouterine curettage under general anesthesia to manual suction $[16,18]$. At the Libreville University in 2005, the proportion of manual suction carried out was $1.7 \%$. In 2016 it rose to $64.5 \%$ and in other countries which have adopted the IFGO initiative it also increased [18]. These figures are below those of Moussa Nouhoum in Ségou (97.1\%) and Leke and Tumasang in Cameroon (100\%) $[7,12,19]$. The EMIA $(64.96 \%)$ appeared easier to achieve. It is easy to use with suction pressure.

\section{Conclusion}

Intrauterine manual aspiration is a safe and effective means of post-abortion care. For several years, this tool has been available to our health center teams. The simplicity of the procedure and its adaptation to our types of structure makes it an indispensable tool in the fight against abortion-related morbidity and maternal mortality in underequipped countries. It is a shared and successful model of competency in our emergency obstetric and neonatal care service [20-23].

\section{Acknowledgement}

Sima Olé B designed the research protocol and wrote this manuscript. Mounguengui O, Mba Edou G, Ebanga L and Mewie Lendzinga A collected the data. Madi Tangani G, Bang Ntamack JA and Obame R participated in the writing. Mayi Tsonga S, Ngou Mve Ngou JP and Meye JF corrected and gave the form to this manuscript. All authors approved the final version of this manuscript.

\section{Conflict of Interest}

The authors do not declare any conflict of interest.

\section{References}

1. (2008) Word Health Organization. Maternal mortality 2018.

2. Shah IH, Ahman E (2010) Unsafe abortion in 2008: global and regional levels and trends. Reprod Health Maters 18(36): 90-101.

3. Ahman E, Shah IH (2011) New trends and trends regarding unsafe abortion mortality. Int J Gynecol Obstet 115(2): 121-126.

4. Mayi-Tsonga S, Diallo T, Litochenko O, Methogo M, Ndombi I (2009) Prevalence of illegal abortion at the Hospital of Libreville, Gabon. Bull Soc Pathol Exot 102(4): 230-232.

5. Shaw D (2014) Origins of the FIGO initiative to reduce the burden of unsafe abortion. Int J Gynecol Obstet 126 (Suppl 1): S3-S6.

6. Directorate General of Statistics (DGS) (2012) Demographic and Health Survey. Ministry of Economy, Libreville, Gabon.

7. Koulibaly MN (2009) Intra-uterine manual aspiration for the management of abortions at the Nianankoro Fomba Hospital in Ségou, thesis, Bamako Mali.

8. Andriamady RC, Rakotoarisoa, Ranjalahy RJ, Fidison A (1999) Cases of abortions at the maternity hospital in Befelatanana in1997. Arch Int Pasteur Madagascar 65(1-2): 90-92.

9. Sedgh G, Keogh SC (2019) Novel approaches to estimating abortion incidence. Reprod Health 16(1): 44.

10. Lokossou A, Adisso S, Komongui DG (2003) Care for incomplete abortions in a reference maternity unit. SAGO Journal 4(1): 7-12.

11. Mayi Tsonga S, Ntamack JB, Sima Olé B, Obiang PA, Minkobame U, Ngouafo D (2014) LARCs after unsafe abortion in Libreville (Gabon): women accept quickly but the time interval for the insertion is longer than that of contraceptive injection. Open J Obstet Gynecol 4(1): 23-27.

12. Leke RJ (2014) Contribution of gynecology and obstetrics societies in West and Central African countries to the prevention of unsafe abortions. Int J Gynecol Obstet 126 (Suppl 1): S17-S19.

13. Mbouwezigolo MAB (1989) Contribution to the study of clandestine abortions. Thesis Medicine, No. 152, Libreville, Gabon, Africa.

14. Reproductive Health Training and Research Center (CEFOREP) (1998) A review of literature on unsafe abortions in Senegal. Operational Research. Technical Assistance Project II in Africa, Population Council, Dakar.

15. Mayi-Tsonga S, Obiang PA, Minkobame U, Ngouafo D, Ambounda N, et al. (2014) Introduction of contraception after abortion, giving priority to long-term reversible contraceptives, in Gabon's main maternity hospital. Int J Gynecol Obstet 126 (Suppl 1): S45-S48.

16. Mayi-Tsonga S, Assoumou P, Olé BS, Ntamack JB, Meyé JF (2012) The contribution of research results to improving in post-abortion care: Libreville Hospital Center (Gabon). Reprod Health Maters 20(40): 1621.

17. Mayi-Tsonga S, Minkobame U, Mbila A, Assoumou P, Diop A, Winikoff B (2014) First experience of the use of Misoprostol as post-abortion care (SAA) in Libreville, Gabon. Pan African Med Journal (Open Access) 18: 301.

18. Minkobame U, Mayi-Tsonga S, Obiang PA, Komba OM, Ella JM (2018) Transient reduction in abortion-related lethality after interventions to reduce the provision of care at Center Hospitalier de Libreville Gabon. Int J Gynecol Obstet 143(2): 247-248.

19. Florence Tumasang, Robert JI, Leke, Valentine Aguh (2014) Extend the use of manual intrauterine aspiration in the event of incomplete abortion in selected health facilities in Yaoundé, Cameroon. Int J Gynecol Obstet 126: S28-S30. 
20. Fawole AO, Diop A, Adeyanju AO, Aremu OT, Winikoff B (2012) Misoprostol as first-line treatment for incomplete abortion at secondarylevel health facility in Nigeria. Int J Gynecol Obstet 119(2):170-173.

21. Venture Strategies Innovations (2012) Maternal lives saved through misoprostol: political and institutional support. SI Revue. 6: 13-15.
22. Kizza AP, Rogo KO (1990) Assessment of the manual vacuum aspiration (MVA) equipment in the management of incomplete abortion. East Afr Med J 67(11): 812-822.

23. Goldberg AB, Dean G, Kang MS, Youssof S, Darney PD (2004) Manual versus electric vacuum aspiration for early first-trimester abortion: a controlled study of complication rates. Obstet Gynecol 103(1): 101-107. 